\title{
How Would Different Parenting Styles Affect Their Children's Exclusive Behaviors?
}

\author{
Zhuge $\operatorname{Yan}^{1}$ \\ ${ }^{1}$ Changzhou NO.1 High School International Department, Changzhou, 213004, China, 2258180247@qq.com
}

\begin{abstract}
Since people might feel painful psychologically and physically when they are excluded, it is necessary to prevent and forecast exclusive behaviors. Parenting styles is an important factor that may forecast children's issue behaviors. Then, it is interesting to know whether and how the three parenting styles, namely authoritative, authoritarian and permissive parenting will influence children's exclusive behaviors. Two questionnaires will be used to test the scale of parents' parenting styles and the scale of children's exclusive behaviors. First, parents will be asked to complete the parenting style questionnaire. Then, their children will be required to do the questionnaire that can test their tendency of behaving exclusively. Finally, a Pearson correlation will be conducted to examine the the relationships between the three parenting styles and children's exclusive behaviors. What is expected to see is that there will be a negative correlation between both authoritative and authoritarian parenting styles and exclusive behaviors, and a positive correlation between permissive parenting and exclusive behaviors.
\end{abstract}

Keywords: Parenting styles, exclusive behaviors, ostracism, impact, Likert scales

\section{INTRODUCTION}

When people are ostracized, being ignored and excluded, they might be hurt both psychologically and/or physiologically [1]. Several studies even demonstrated that people who have been targets of ostracism might target others for violent acts [2]. Therefore, according to all these negative effects of ostracism, it is necessary to try to prevent and forecast people's exclusive behaviors which will make others lose belonging. For security, reproductive success, and mental health, a sense of belonging is essential [3].

Parents have significant influence on a person's life, and according to studies, the notion of parenting style is one of the most researched methods to understand parental influences on human development [4]. In forecasting children's issue behaviors, studying parenting styles would be most influential [5]. Since parenting styles have an impact on children's behaviors, how would different parenting styles, namely authoritative parenting, authoritarian parenting, and permissive parenting proposed by Baumrind(1967)[4] affect children's exclusive behaviors remains a question. By solving this question, people can then be informed the parenting style which is least likely to lead to children's exclusive behaviors and apply it.
According to the way Diana Baumrind(1967) categorized the three parenting styles, assumptions can be made about how different parenting styles make an impact on children's exclusive behaviors. For parents who use authoritative parenting style, they have the ability to control their children while making their children willing to follow their rules because they combine warmth and reasonable control. Thus, their children will be less likely to exhibit exclusion. For Children under authoritarian parenting style, they may have a lower tendency to exclude others as well since their parents want their obedience with punitive and forceful measures. Under such parenting style, children will be less likely to behave antisocially since their parents value preservation of order and traditional structure, so their children might not exclude others often. However, parents whose preferred parenting style is permissive parenting might have children who have strong tendency of exclusive behaviors because children under permissive parenting style will be rebellious and defiant when their wishes are challenged.

\section{PRESENT WORK}

To study how different parenting styles suggested by Baumrind(1967) influence their children's exclusive behaviors, we will do a correlational study separately. The 
Parenting Style Questionnaire (Robinson, C., Mandleco, B., Olsen, S. F., \& Hart, C. H., 1995) will be used to test which parenting style the parents are more likely to use and the score they get of their preferred parenting style(the highest calculated score).[6] Exclusive behaviors can be measured by recomposing the Ostracism Experience Scale for Adolescents (OES-A) developed by Gilman, Carter-Sowell, DeWall, Adams, and Carboni (2013).[7] Since scales that are used to test to which level people may have exclusive behaviors could not be easily found, we decided to develop a scale to measure the level of exclusive behaviors in our research based on the Ostracism Experience Scale for Adolescents (OES-A). The reliability of this scale is guaranteed since the Cronbach's Alpha is tested as .916 by using predicted numbers, which means that this test is very reliable. After acquiring the scores of each parenting style and the tendency level of their children's exclusive behaviors, we will use Pearson Correlation to analyze the correlation.

\section{STUDY 1}

What we expect to learn is the respective correlations between the three parenting styles and their children's exclusive behaviors, and we will use the same method to acquire their correlations. Negative correlations of both authoritative and authoritarian parenting styles with their children's exclusive behaviors are estimated. Additionally, we expect positive correlation between permissive parenting style and exclusive behaviors.

\section{METHOD}

4.1Participants. In the research proposal, we expect to have 3000 one-child families in total as our participants, 1000 families in each parenting style. However, in our simulation of the research, only 90 one-child families will be selected in this study from all the family participants surveyed by the Parenting Style Questionnaire. Then, 30 of the families categorized as each parenting style will be respectively randomly selected and included in the study. Thus, in total, our participants will include parents and the children in those 90 one-child families.

4.2 Measures. In our simulation of the research, 90 one-child families will be selected in this study from all the family participants surveyed by the Parenting Style Questionnaire. On a six-point scale, scores range from "Never" to "Always." Parents' preferred parenting style is determined by the highest calculated score. According to the Parenting Style Questionnaire (Robinson, C., Mandleco, B., Olsen, S. F., \& Hart, C. H., 1995), there are thirteen questions for Authoritarian and Authoritative parenting styles, and for permissive parenting style, there are 4 questions for parents to answer. To obtain the calculated score for that category, tally up the scores at the end of each part and divide the total by the number of questions in that section. All the family participants who are surveyed by the questionnaire will be categorized as authoritative, authoritarian, and permissive parenting based on the highest score they get in this questionnaire. The children in the families selected in the research will be required to complete a questionnaire that is used to rate exclusive behaviors. This questionnaire is developed by us based on Ostracism Experience Scale for Adolescents (OES-A) proposed by Gilman, Carter-Sowell, DeWall, Adams, and Carboni (2013).

Table 1 Scale to rate exclusive behaviors

\begin{tabular}{|c|c|c|c|}
\hline \multicolumn{3}{|c|}{ Scale to rate exclusive behaviors } & \\
\hline \multicolumn{3}{|l|}{ In general, I } & \\
\hline \multicolumn{4}{|l|}{ Ignoring subscale } \\
\hline \multicolumn{4}{|c|}{...treat others as if they are invisible } \\
\hline \multicolumn{4}{|c|}{...do not look through others as if they do not exist } \\
\hline \multicolumn{4}{|c|}{...ignore others' greetings when we are walking by one another } \\
\hline \multicolumn{4}{|c|}{...ignoring others during conversation } \\
\hline \multicolumn{4}{|l|}{...do not ignoring others } \\
\hline \multicolumn{4}{|c|}{ ' } \\
\hline \multicolumn{4}{|l|}{ Excluding subscale } \\
\hline \multicolumn{4}{|c|}{...do not "hang out" with others at my home } \\
\hline \multicolumn{4}{|c|}{...invite others to join my club, organization, or association } \\
\hline \multicolumn{4}{|c|}{...do not include others in my plans for the holidays } \\
\hline \multicolumn{4}{|c|}{...make an effort to get others attention } \\
\hline \multicolumn{4}{|c|}{...do not invite others to go out to eat with me } \\
\hline \multicolumn{4}{|c|}{...do not invite others to join me for weekend activities, hobbies, or events } \\
\hline \multicolumn{4}{|c|}{ 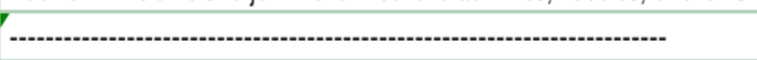 } \\
\hline \multicolumn{4}{|c|}{ Note: This scale includes two subscales: Ignoring and Excluding subscale. } \\
\hline \multicolumn{4}{|c|}{ The ignoring subscale assesses the extent to which an adolescent makes } \\
\hline \multicolumn{4}{|c|}{ others feel being socially rejected and excluded by the peer group. } \\
\hline \multicolumn{3}{|c|}{ (1)-Never (2)-Rarely (3)-Sometimes (4)-Often (5)-Always } & \\
\hline
\end{tabular}

4.3Procedures. All the parents who take part in this study need to complete the Parenting Style Questionnaire. After rating by the questionnaire, 30 of the families categorized as each parenting style will be respectively randomly selected and included in the study. Then, the children of the families included will be required to complete the questionnaire that is used to rate the scale of exclusive behaviors.

4.4 Data Analytic Approach. A Pearson correlation method will be used to analyze the predicted data in the simulation study by SPSS Statistics.

\section{RESULTS}

As shown in Figure 1, authoritative parenting style is strongly negatively related to exclusive behaviors, $r(28)=-$ $0.706, \mathrm{p}<0.001$ 


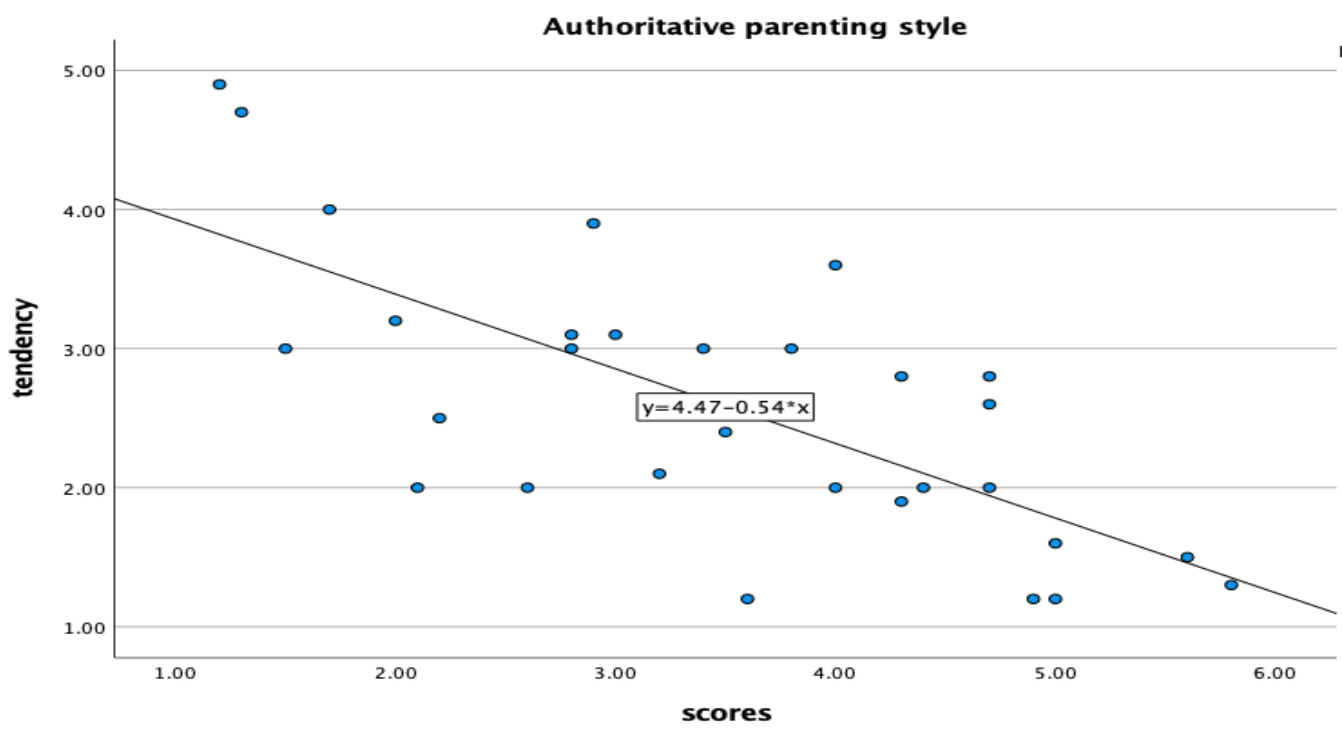

Figure 1. Scores represent the score parents get in the parenting style questionnaire. The tendency represents the scale, from 1 to 5 , of children's exclusive behaviors.

According to Figure 2, authoritarian parenting can find little correlation according to its r-value and $p$-value, $r(28)=-0.336, p=0.07$. Since $p$-value is more than 0.005 , we can not reject the null. The two variables are not linearly negatively related to each other as we predicted.

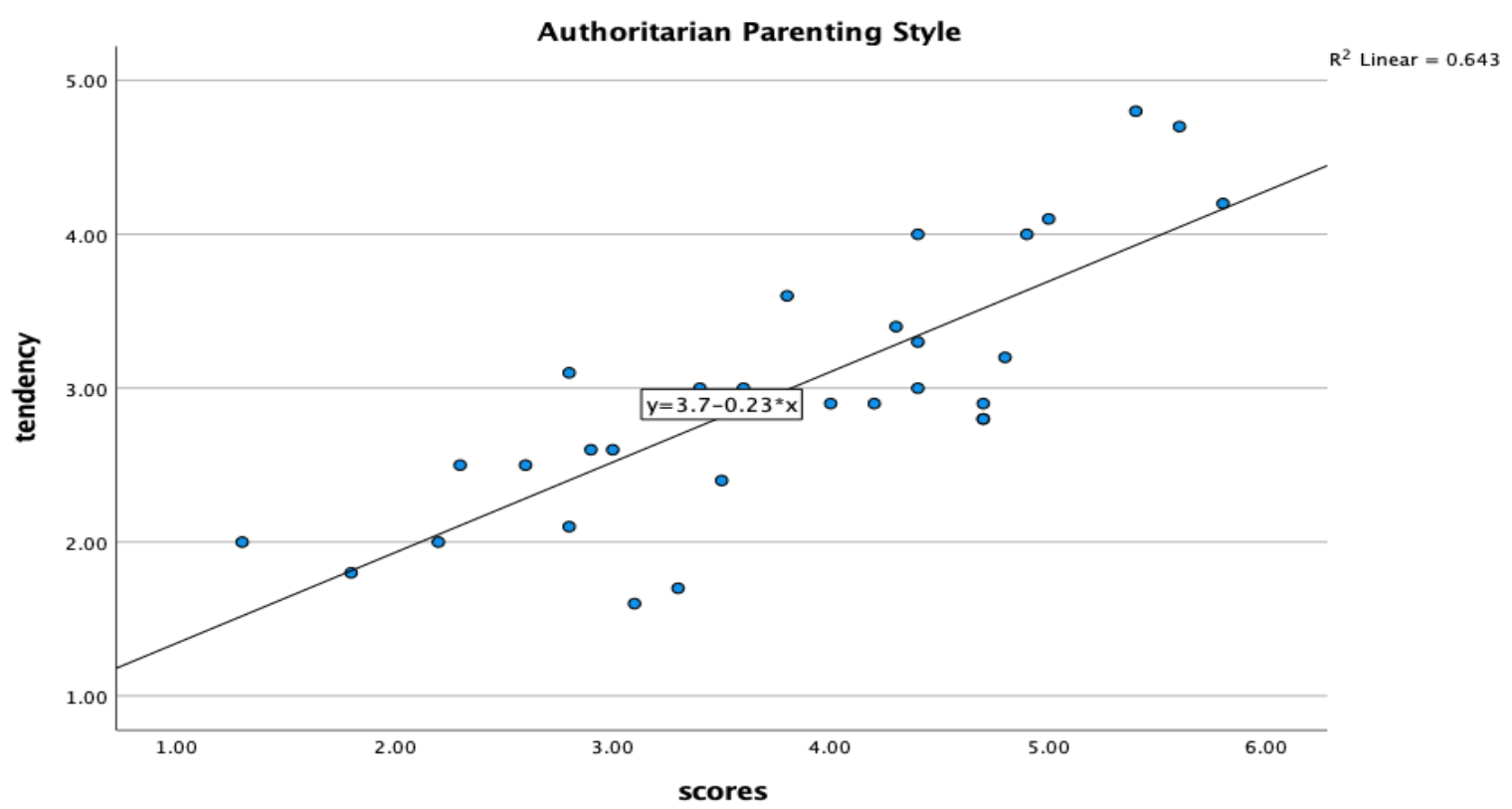

Figure 2. Scores represent the score parents get in the parenting style questionnaire. The tendency represents the scale, from 1 to 5 , of children's exclusive behaviors.

As shown in Figure 3 Permissive parenting style is strongly positively related to exclusive behaviors, $\mathrm{r}(28)=0.802, \mathrm{P}<0.001$. 


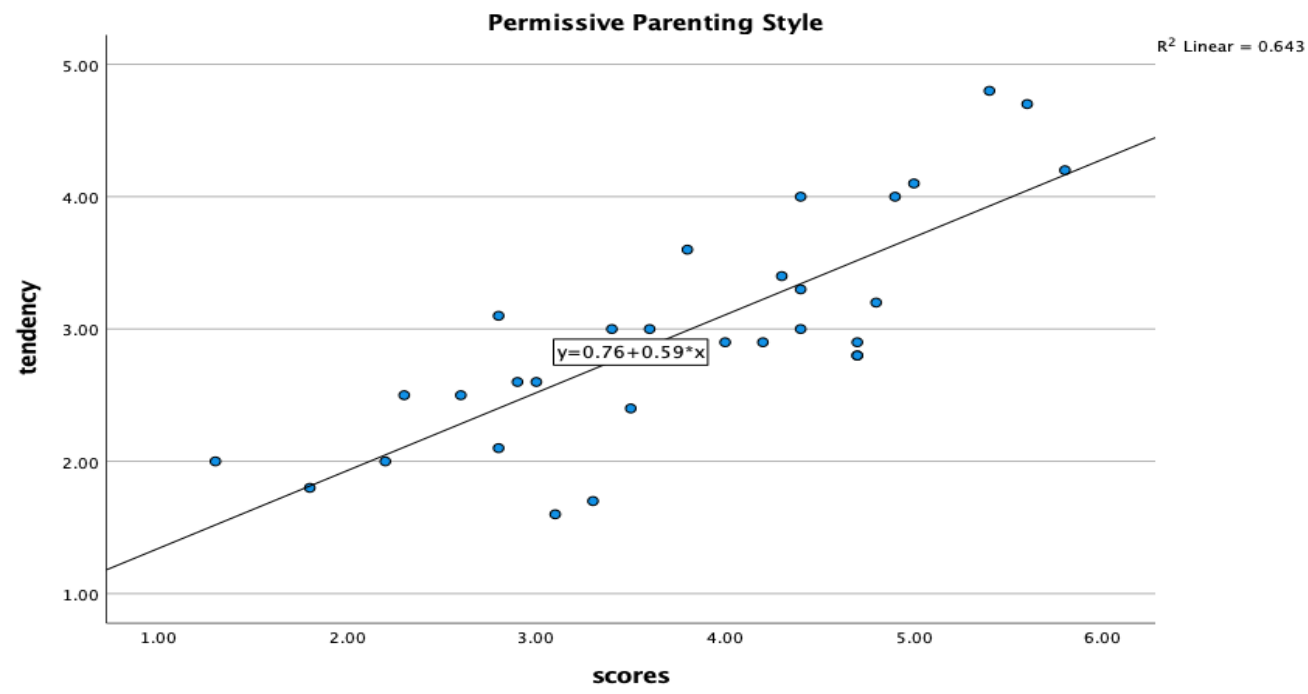

Figure 3. Scores represent the score parents get in the parenting style questionnaire. The tendency represents the scale, from 1 to 5 , of children's exclusive behaviors.

\section{CONCLUSION}

According to the simulation of the research, we found that the predicted results of the correlation of authoritative and permissive parenting styles with children's exclusive behaviors confirmed our original hypothesis. Under authoritative parenting style, children are less likely to have exclusive behaviors, and under permissive parenting, children are more likely to behavior exclusively. However, the correlation between authoritarian parenting style and exclusive behaviors is not consistent with our prediction according to predicted results. Authoritarian parenting shows little correlation according to data analysis. What we found shows that authoritative parenting style should be more recommended to use since under such parenting children show fewer exclusive behaviors, which may reduce ostracism.

However, there are some limitations as well. First, since it is just a simulation, the number of participants is small and the results may not be accurate. The study can be done in the future with 3000 participants, which will be more accurate. Moreover, since in one's life, parenting styles are just one factor that may influence their behaviors, there are still many other variables that I may ignore, and future studies can focus on other factors like teaching style in school, social support, and their own personality.

\section{REFERENCES}

[1] Williams, K. D., \& Nida, S. A. (2011). Ostracism. Current Directions in Psychological Science, 20(2), $71-75$. https://doi.org/10.1177/0963721411402480

[2] Williams, K. D. (2007). Ostracism. Annual Review of Psychology, 58(1), $425-452$. https://doi.org/10.1146/annurev.psych.58.110405.0 85641

[3] Baumeister, R. F., \& Leary, M. R. (1995). The need to belong: Desire for interpersonal attachments as a fundamental human motivation. Psychological Bulletin, 117(3), 497-529. https://doi.org/10.1037/0033-2909.117.3.497

[4] Baumrind, D. (1967). Child care practices anteceding three patterns of preschool behavior. Genetic Psychology Monographs, 75(1), 43-88.

[5] Aunola, K., \& Nurmi, J.-E. (2005). The role of parenting styles in children's problem behavior. Child Development, 76(6), 1144-1159. https://doi.org/10.1111/j.1467-8624.2005.00840.xi1

[6] Robinson, C. C., Mandleco, B., Olsen, S. F., \& Hart, C. H. (1995). Authoritative, authoritarian, and permissive Parenting Practices: Development of a new measure. Psychological Reports, 77(3), 819830. https://doi.org/10.2466/pr0.1995.77.3.819 ofin

[7] Gilman, R., Carter-Sowell, A., DeWall, C. N., Adams, R. E., \& Carboni, I. (2013). Ostracism experience scale for adolescents. PsycTESTS Dataset. https://doi.org/10.1037/t29695-000 